\title{
Is internationalisation really an available choice for micro firms producing Cava and Prosecco Superiore? A cross-country, entrepreneurial action perspective
}

\author{
Duarte Alonso, A. and Kok, S.K.
}

\begin{abstract}
Purpose - The purpose of this study was to examine pathways towards, and the rationale behind internationalisation from the perspectives of micro firms' operators involved in the globally competitive wine industry. Moreover, drawing from entrepreneurial action theory, the study developed a theoretical framework to help understanding micro approaches and rationale for internationalisation.

Design/methodology/approach - Data were collected through interviews with 19 micro winery owners and managers operating in the Prosecco Superiore (Italy) and Cava industry (Spain).

Findings - Aligned with entrepreneurial action theory, uncertainty in participants' environment, coupled with the associated need to diversify through exports, were predominant drivers of internationalisation. However, internationalisation also emerged through non-deliberate channels, including through growth of wine tourism and increasing foreign wine enthusiasts. Thus, while entrepreneurial action through deliberate means triggered a stronger focus on internationalisation, other passive interventions beyond the control or influence of micro firms, but rather emerge serendipitously, can similarly spur direct action.

Originality/value - The study demonstrated its originality and value in various ways, fundamentally, addressing three knowledge gaps, thereby contributing to practical and theoretical discourses with corresponding value, including managerially. First, it extended literature focusing on micro firms, which as compared to small and medium enterprise research is much more limited. Second, it provided a comparative component, which is much rarer in contemporary research discussing internationalisation among micro firms. Third, the study proposed a theoretical framework stemming from the chosen inductive approach, thus, addressing concerns regarding the lack of theoretical rigour or depth in internationalisation activities among micro firms.
\end{abstract}

Keywords: Entrepreneurial action, micro firms, internationalisation, cross-country dimension, uncertainty.

\section{Introduction}

Internationalisation of firms

Different academic contributions have sought to expand knowledge of processes, factors, and the rationale for small firm internationalisation (e.g., Cerrato et al., 2016; Zhang et al., 2016). Among other definitions, internationalisation has been conceptualised as the process of firms' "increasing involvement in international operations" (Welch and Loustarinen, 1988, p. 36). Internationalisation includes modified positions and perspectives, and it represents a significant dimension of ongoing strategic processes for the majority of firms (Melin, 1992). These strategic processes define ongoing changes and development among international firms regarding such aspects as organising principles, action orientation, business idea, dominating values, or scope (Melin, 1992).

Research on small and medium enterprises (SMEs) (Dutot, Bergeron, and Raymond, 2014) suggests that firms' ability to internationalise has become a key competitive necessity, enabling them to enter larger markets and increasing their chances of survival. For these firms, innovative capabilities can be an essential ingredient to increase their international involvement, especially when prior growth is exceeded or unmet (McCormick and Fernhaber, 2018). Hermel and Khayat (2011) also highlight the significance of innovation, alongside networks and managerial capabilities, as triggers of rapid micro-firm internationalisation. 
Similarly, D'Angelo et al. (2013) found that product innovation, networking and human resources had a positive impact on SMEs' export performance regardless of their export destination. However, exporting beyond familiar markets exposes SMEs to the complexities of foreignness; thus, to succeed in global export markets, more specialised and dedicated resources, such as hiring specialists or investing more in product innovation (D'Angelo et al., 2013) are needed. In this context, a study focusing on Czech SMEs (Musteen, Francis, and Datta, 2010) ascertained the importance of sharing a common language with international ties as a tool to achieve faster internationalisation.

\section{Research-knowledge gaps}

Despite a plethora of research focusing on SME internationalisation, various research gaps remain. For example, Zhang et al. (2016) claim that the precise ways in which international entrepreneurship network ties and characteristics interact to influence internationalisation of SMEs in emerging markets remains poorly understood and under-theorised. Among other conceptualisations, entrepreneurship has been defined as the establishment of new enterprises by small groups or individuals, with the entrepreneur taking up the role of a key agent of change (Kent, Sexton, and Vesper, 1982).

More specifically in the context of the present empirical examination, while international entrepreneurship research has grown rapidly in the last few decades, little attention has been devoted to the dimension of internationalisation among micro-sized firms (McCormick and Fernhaber, 2018). Moreover, because of "influence of the entrepreneur within these microsized ventures, an especially relevant question is how entrepreneurial perceptions impact international growth" (McCormick and Fernhaber, 2018, p. 591). Furthermore, and partly aligned with a review of SME research (Paul, Parthasarathy, and Gupta, 2017), the academic micro firm literature focusing on internationalisation initiatives and activities lacks theoretical depth and rigour. Finally, limited attention has been paid to investigating micro firm internationalisation employing a comparative, cross-country approach. Given that micro and small firm research is typically included the SME category (Donner, 2006), this study will predominantly draw on the SME literature to develop appropriate discourses on micro firm internationalisation.

The European Commission (2003) defines micro enterprises as those employing less than 10 employees. SMEs constitute $99.8 \%$ of businesses in the European Union; of these, almost 93\% of these are micro in size (European Commission, 2016). Given this evidence highlighting the significance of micro businesses, including for the European Union, shedding light on aspects related to internationalisation initiatives and efforts within this group of firms could provide valuable insights, including for industry practitioners, as well as for policy makers and the academic community.

\section{The study's objectives and research questions}

The present study will fulfil various objectives to advance practical discourses and theoretical underpinnings of current micro and small business entrepreneurship literature. Essentially, the study fulfils a first objective by narrowing the research gap acknowledged by McCormmick and Fernhaber (2018), regarding scant research on internationalisation among micro businesses. Moreover, in gathering the viewpoints of owners-managers in two separate countries concerning internationalisation of their firms, in this case, in the wine industry, the study addresses a second research gap. To examine these two areas needing further attention from the literature, the following research questions (RQs) are examined:

RQ1: How are the studied micro firms currently internationalising? More specifically, in what ways or through which means are these firms internationalising? 
RQ2: Why are they internationalising?

These overarching questions align with the knowledge gap identified in recent research (McCormick and Fernhaber, 2018) concerning the need to address the question of how the perceptions of entrepreneurs of micro-sized firms affect their growth internationally. Thus, apart from extending literature on micro firm internationalisation, new knowledge addressing the above questions could also illuminate paths towards internationalisation, motivating or persuading firm's owners-managers to increase their international involvement in various ways, with implications for their businesses' bottom line and overall, for regional development. Furthermore, new data gathered from experienced, knowledgeable individuals will be extremely valuable to other stakeholders, including owners-managers in the broader wine industry (e.g., sparkling versus still wines), importers, chambers of commerce, local wine associations, or even business development agencies.

From a theoretical standpoint, the study draws on entrepreneurial action theory (e.g., McMullen and Shepherd, 2006; Mitchell and Shepherd, 2010) to develop a deeper understanding concerning the significance of opportunity identification for micro firms, both through active and passive means, thereby helping them achieve entrepreneurial growth while countering uncertainty. Following this reflective process, and based upon the selected inductive approach of qualitative data analysis (Thomas, 2006), a theoretical framework depicting the key emerging themes associated with various insights of entrepreneurial action theory will be proposed.

\section{Literature Review}

\section{Uncertainty, risk, and entrepreneurial action theory (EAT)}

Paul et al. (2017) explain that there have been pervasive challenges in harnessing the potential of 'comprehensive theories' to processes and decisions associated with the internationalisation of small enterprises. While the present study does not propose any particular internationalisation-based theories, it nevertheless identifies aspects between EAT and its findings. More importantly, based upon the inductive approach undertaken, the study will illustrate the associations between both in a proposed theoretical framework. In doing so, the study facilitates understanding of internationalisation among micro firms operating in a competitive and uncertain wine business environment (Thomas, Painbéni, and Barton, 2013). The suggested usefulness of this theory to study micro enterprises involved in the wine industry therefore warrants its adoption. Anderson (2000) refers to Schumpeter (1934) to stress that internationalisation is an illustration "of strategic change that can be defined as an entrepreneurial action" (p. 68). Furthermore, in the domain of multinational corporations, entrepreneurial action is underlined as an element, which enables firms to harness the potential of internationalisation, including through their resource bundles (Madhok and Keyhani, 2012).

According to Dominguez and Mayrhofer (2017), changes in the global economy can significantly affect SMEs. From an empirical perspective, research exploring manufacturing SMEs (Raymond and St-Pierre, 2013) underlines the situations of uncertainty experienced by these firms, requiring constant "adjustments to their business processes" (p. 97), including flexibility to counter changes taking place in their business environment. Moreover, turbulence represents an environmental condition, which underlies business risk and uncertainty (Westhead, Wright, and Ucbasaran, 2004). Overall, entrepreneurship entails operating at a certain level of uncertainty; therefore, being able to interpret and counter uncertainty often determines a firm's ability to succeed (McKelvie, Haynie, and Gustavsson, 2011). In contrast, risk propensity has been found to relate positively to entrepreneurial intentions (Zhao, Seibert, and Lumpkin, 2010). Furthermore, entrepreneurs who perceive 
turbulence in the external environment may be persuaded to identify and maximize opportunities (Westhead et al., 2004). On the other hand, changes in the global business environment can provide untapped opportunities for growth (Dominguez and Mayrhofer, 2017).

In alluding to earlier research by Mises (1949), McMullen and Shepherd (2006) posit that, given that action occurs over time, and that the future cannot be fully known, action is essentially uncertain. Not surprisingly, uncertainty conceptually represents the cornerstone of theories of entrepreneurship, and unwillingness to tolerate uncertainty is considered to prevent future entrepreneurs from participating in entrepreneurial action (McMullen and Shepherd, 2006). According to McKelvie et al. (2011), entrepreneurship entails a certain level of uncertainty; therefore, being able to interpret and counter uncertainty often determines a firm's ability to succeed- or fail. Uncertainty can lead to doubt and prevent action, undermining beliefs among prospective entrepreneurs concerning whether:

- An environmental stimulus creates opportunities in the marketplace for individuals.

- These opportunities can be performed feasibly by an actor (the entrepreneur).

- The successful exploitation of these opportunities would satisfy some personal desire adequately (McMullen and Shepherd, 2006).

Consequently, McMullen and Shepherd (2006) propose that several elements related to action, such as knowledge, motivation and stimulus, should be contemplated when deciding to act or not act entrepreneurially. Moreover, they subscribe to the work by Hébert and Link (1988) which suggests that an entrepreneur responds to and creates changes through entrepreneurial action. In addition, drawing from previous academic research (Gartner, 1990; Shane and Venkataraman, 2000), McMullen and Shepherd (2006) define entrepreneurial action as "behavior in response to a judgmental decision under uncertainty about a possible opportunity for profit" (p. 134).

The above principles and notions led to the development of a conceptual model featuring two stages, with clear distinctions between them. The first stage, opportunity attention, comprises questions of why opportunities are identified and maximised in general, or thirdperson opportunities (Mitchell and Shepherd, 2010). This stage is depicted in three dimensions, linking knowledge (prior knowledge) and motivation (personal strategy) to third person opportunity (McMullen and Shepherd, 2006). This last dimension subsequently links to two dimensions pertaining to the second stage, opportunity evaluation, which concerns questions of why opportunities are spotted "and acted upon by specific individuals" (p. 140), or first-person opportunities. The two dimensions, knowledge (feasibility assessment) and motivation (desirability assessment) result in entrepreneurial action (McMullen and Shepherd, 2006).

Alvarez and Barney (2007) also refer to discovery and creation theories to explain more specifically the nature of opportunities. Indeed, discovery theory suggests the existence of opportunities independently of entrepreneurs. Creation theory suggests the opposite, namely, that opportunities do not exist independently of entrepreneurs (Alvarez and Barney, 2007); thus, creation theory emphasises the role and action of entrepreneurs. Importantly, Alvarez and Barney (2007) identify a number of effective entrepreneurial actions that apply in discovery and creation contexts, including strategy, marketing, finance, decision making, human resource practices, leadership, and sustaining competitive advantage.

Studies have highlighted the potential of entrepreneurial action in various industries or domains. For example, Dean and McMullen (2007) agree that entrepreneurial action can help lessen such environmental challenges as degradation, by overcoming obstacles to the efficient performance "of markets for environmental resources" (p. 51). Furthermore, Dean and 
McMullen (2007) contend that there is a growing desire among numerous individuals to curtail environmentally damaging activities, including a willingness to pay. As a result, there are opportunities for entrepreneurial action that, in this case, lead to enhancing ecological sustainability (Dean and McMullen, 2007).

Overall, however, the SME literature has not fully embraced the potential of EAT to understand how entrepreneurs seek to identify and maximise opportunities, including through internationalisation, while bearing uncertainty. The few existing SME-related studies only symbolically refer to entrepreneurial action, without any subsequent in-depth discussion or analysis. For instance, in the field of marketing SMEs, Bettiol, Di Maria, and Finotto (2012) acknowledge that entrepreneurs seek to make sense of their business environment, developing evocative or powerful concepts that facilitate entrepreneurial action and ensuing innovation and strategic renewal. The knowledge gap regarding the lack of employing EAT to understand both entrepreneurial activity and internationalisation is also evident in micro firm research.

The fundamental purpose of the present study is to examine empirically internationalisation among micro enterprises operating in a competitive global industry. In doing so, the study addresses some of previously identified empirical and theoretical gaps concerning micro firm internationalisation (McCormick and Fernhaber, 2018), and the paucity of theoretical application to understand small firm internationalisation (Paul et al., 2017).

\section{Methodology}

In drawing from EAT, this study examined aspects related to internationalisation among micro firms in two different countries (Italy, Spain) operating in the global wine industry that faces strong competition and uncertainty (Anderson and Wittwer, 2017). Thus, the study's unit of analysis, the "bounded set of elements comprising the entity which is the focus of research" (Gronn, 2002, p. 444) was represented by internationalisation processes and experiences gathered from micro winery entrepreneurs and managers in two separate countries. Firms in Italy and Spain were selected based upon these nations' long history and relevance in wine production, being two of the world's top three wine producing and wine exporting nations (Statista, 2020a, 2020b).

In line with earlier research on small firm internationalisation (Bell, Crick, and Young, 2004; Hermel and Khayat, 2011), a qualitative methodology was also chosen; it was based on semi-structured, in-depth interviews among representatives (owners, managers) of micro wineries. However, other forms of data collection, including archival firm information and observations were also part of the examination. Together, these additional information sources related to triangulation of data (Woodside and Baxter, 2012), and were manifested in various forms. Indeed, during the winery visit, the research could observe visitor flow, interaction between the owner-manager-staff and visitors; further, often the winery had written materials (brochures) the researcher could refer to before or after the interview. Triangulation thus complemented or further reinforced information not clearly articulated by the participant (Woodside and Baxter, 2012).

Associated with qualitative research, the study undertook inductive analysis, which entails approaches mainly employing thorough readings of raw data to develop themes, concepts or models originating from (raw data) interpretations made by researchers or evaluators (Thomas, 2006). More precisely, Thomas (2006) noted that one key purpose of the approach is to "develop a framework of the underlying structure of experiences and processes that are evident in the raw data" (p. 236). The study's proposition of a theoretical framework (Figure 1) emanating from the associations between EAT and the findings clearly aligned with Thomas's (2006) discourse. Furthermore, this analysis allowed research findings to come 
forward from the significant, dominant, of frequent themes that are characteristic in raw data (Thomas, 2006).

Regarding the study's participants, Patton (2015) explained the importance of purposive sampling, in other words, the strategic selection of information-rich cases to examine, which, by their substance or nature, can help illuminate the inquiry-related questions under examination. Aligned with Patton (2015), this study sought the participation of individuals whose experience, knowledge, and skills would help answer fundamental questions (RQ1, RQ2). Complementing the purposive sampling method, a constructivist paradigm was adopted. One key characteristic of this paradigm is the importance of interactions between the researcher and the subject under investigation; fundamentally, this interaction can generate or uncover deeper meaning (Ponterotto, 2005).

In September of 2016, 88 wineries were identified through searches in individual and winery association websites in the regions of Valdobbiadene (Italy), and Sant Sadurní d'Anoia (Spain). These firms were contacted through electronic email correspondence, which entailed a brief introduction to the study and an invitation for the winery's owner or manager to take part in the research. As many as 19 micro firms, 10 in Italy and 9 in Spain, accepted the invitation to be visited and interviewed during the summer of 2017 (Table 1). In the months of June and July of 2017, one member of the research team who is fluent in Spanish and Italian visited the wineries to conduct the interviews; these lasted approximately 70 minutes and were audio recorded with participants' permission.

\section{Table 1 Here}

The following protocol was adhered to: first, basic questions were asked concerning the participant's and/or firm's characteristics, including the age of the firm, years of working at the winery among participants, involvement in exports, and whether or not the winery exported or was under the ownership of a family (Table 2). Second, the following open-ended questions were asked:

Q1: How is your winery currently internationalising? In other words: in what ways is it internationalising?

Q2: Why is your winery internationalising? What are the main reasons for internationalising?

Various academic contributions, particularly those focusing on SME internationalisation (e.g., Bell et al., 2004; Cerrato et al., 2016; Crick and Spence, 2005; D’Angelo et al., 2013; Musso and Francioni, 2015; Zhang et al., 2016), were consulted in the process of developing the questionnaire tool.

While the literature concerning data saturation, or "when the researcher gathers data to the point... when nothing new is being added" (Bowen, 2008, p. 140) is still inconclusive (Fusch and Ness, 2015), O'Reilly and Parker (2013) considered the appropriateness of the data, as opposed to the number of participants, as the key marker. In this study, the relevance of the data collected by the $19^{\text {th }}$ interview with micro winery representatives was in alignment with O'Reilly and Parker's (2013) suggestion; therefore no further interviews were conducted.

The collected audio data were transcribed and translated into English and cross-checked by all members of the research team for accuracy and consistency. The data were then analysed employing qualitative content analysis, which consists of subjectively interpreting content of text data, by systematic classification based on coding and identification of patterns and themes (Hsieh and Shannon, 2005). This analysis was supported by the data management NVivo, version 11, and by computer-assisted qualitative data analysis software (CAQDAS) (García-Horta and Guerra-Ramos, 2009). 
Data drawn from observations and archival information were also analysed in NVivo (version 12), where key themes were identified alongside qualitative interviews. Archival data in the form of documentation available and provided by each winery as well as any additional records were utilised in examining the different cases.

\section{Demographic characteristics: Industries, participants and firms}

This study takes a cross-country approach, examining micro enterprises involved in the production of two distinct products (Prosecco Superiore, Cava) and operating in two different regions (Valdobbiadene, Italy; Sant Sadurní d'Anoia, Spain). Figures from a 2016 annual report (Conegliano-Valdobbiadene, 2016) illustrate that, in 2015, 76.7 million bottles of Prosecco Superiore were produced, of which, $59.1 \%$ were destined to the domestic and $40.9 \%$ to the export market. The international market was estimated at 32.1 million bottles and a value of 157.4 million Euros in 2015, 7.5\% more in value than in 2014 (ConeglianoValdobbiadene, 2016). The European Union (EU), with 67 of total exports, is Prosecco Superiore's main market (Conegliano-Valdobbiadene, 2016).

In comparison, the Designation of Origin Cava (DO Cava, 2018) documents that, in 2017, 252.5 million bottles of Cava were produced, for total value of 1.15 billion Euros. As much as $44 \%$ of production was exported to the EU, $20 \%$ to markets outside the EU, and $36 \%$ was sold in the domestic market (DO Cava, 2018).

All the participating firms employed fewer than nine full-time personnel (Table 2), and therefore aligned with the European Commission' (2003) definition of micro enterprises. In addition, all were family-owned at the time of the study. Both participant groups exhibited very similar year average working in the wine industry (Italy: 17.2 years; Spain: 18 years), with the overall average being 17.6 years. All Spanish, as well as the large majority of Italian participants (7) were the owners/co-owners of the winery.

Table 2 Here

\section{Results}

How micro firms are internationalising

The comments from the two groups of participants regarding how they internationalise illustrate strong similarities between the two countries, as well as key differences (Table 3). As would be expected, exports represented a key deliberate form of engaging in internationalisation. Indeed, all firms were involved to some degree in exports, namely, between $5 \%$ to just over $50 \%$ of production was exported to different markets, with an intention to increase steadily. These findings support previous research among SMEs in the wine industry (Duarte Alonso et al., 2014), which underlined the significance of exports for wineries' strategy, especially in response to such challenges as market competition, detrimental currency exchanges, and issues of trust with international business partners, all causes of uncertainty.

Overall, the findings also provide support to previous research (Andersson, Gabrielsson, and Wictor, 2004) emphasising that the fast-changing and dynamic business environment in which firms operate encourages or pushes them to internationalise, expanding their international efforts. In fact, all but one firm were also considering increasing this side of the business. Only Spain4 did not consider any further exports due to the limited size of the winery, and the need to consolidate the brand in the Catalonian/Spanish market: "We want to expand, first, in the proximity." However, the participant was keen to increase the winery's involvement in wine tourism: "my son just finished his degree in oenology; he is excited about growing in wine tourism. He speaks English; somehow, he also takes care of social media." Based on the content of all cases, the wine tourism phenomenon has been growing 
alongside the studied wine regions for decades, without any apparent direct action from wine producers in the initial stages to spur such growth. Furthermore, the tone of many of the comments, including the following, suggested that the development of wine tourism was not only mainly based on a serendipitous phenomenon, but also taken for granted, and that it was up to wineries to exploit and maximise any potential opportunities:

\section{Italy3: Tourism is growing in this region. I have also noticed that many visitors are coming further away... We see more often younger visitors... \\ Spain1: What has changed is the wine tourism phenomenon. We receive numerous families interested in wine and Cava.}

International wine tourism research (e.g., Duarte Alonso et al., 2015) revealed different benefits of involvement in wine tourism for wineries, including in the form of promotion, particularly through work-of-mouth advertising, increased networking with importers, and on-site sales.

Another external issue that appeared to be strongly associated with serendipity, and at the same time unrelated to wineries' strategic action and intent, was the increased popularity of the products. Indeed, comparing between firms from both countries, Italian participants clearly agreed more than their Spanish counterparts. Essentially, the rise in consumption and preference in various markets for Prosecco DOC (controlled designation of origin) was perceived as a key trigger in the demand for this product. Moreover, while Prosecco Superiore DOCG (superior controlled designation of origin) was targeted to a different, higher-end consumer audience, the usefulness and collateral impacts the various initiatives and efforts accompanying the wider promotion, marketing, and distribution of Prosecco had for their product were recognised. Italy4, for instance, posited "There has been a Prosecco 'boom' almost worldwide, which did not exist 10 years ago. We are trying to position ourselves at a higher level in the Prosecco market. In contrast, only two Spanish participants (Spain5, Spain6) commented on the rise in popularity and demand of Cava products, especially in Europe.

\section{Table 3 Here}

\section{Why micro firms are internationalising}

Table 3 also identifies five different dimensions through which internationalisation is triggered. First, and paradoxically, the wine tourism phenomenon, which has grown in the studied regions in a seemingly independently way without any direct action from the wineries, constitutes a direct reason why wineries are increasingly internationalising. Spain2, for instance, who clearly valued and appreciated the potentially beneficial long-term effects of embracing wine tourism as an internationalisation strategy, explained: "I will be travelling to China; I intend to build synergies for future potential opportunities, such as hosting Chinese wine tourists. Synergies are crucial, and so is hosting people because you never know what might happen in the future." This comment aligns with Musso and Francioni's (2015) research on SME internationalisation, more specifically, on agri-food clusters, in that networks represent a fundamental factor for firms to internationalise. Furthermore, among other forms of building relationships, visiting tourists constituted a key method to building such networks (Musso and Francioni, 2015).

The popularity of the product, as clearly illustrated among Italian participants, was not only how they were internationalising, but also further suggested a reason as to why they were doing so; this dimension was very differently perceived by both groups. Indeed, Italian wineries can take advantage of the current strong momentum that Prosecco is experiencing, 
which subsequently can help position the Prosecco Superiore product, or, in the case of some Cava producers (Spain5, Spain6) enter new markets by persuading importers and consumers to try new products.

Another key difference between the two countries was manifested by the political climate, where internal turmoil was having a negative effect on the region's products. Moreover, several participants expressed their concern at what they perceived as a boycott of Cava in other parts of Spain. The concern this situation created persuaded some winery operators (e.g., Spain1, Spain2, Spain7) to redouble their efforts and seek further internationalisation. As Spain1 explained: “... with the current political climate it is quite difficult to sell... We are starting to explore other markets, and just started exporting to the USA."

Furthermore, the Brexit phenomenon, or the outcome of a 2016 referendum in the United Kingdom (UK) to leave the European Union, was perceived by both groups as a challenge to internationalisation, and therefore as a reason for wineries to search for other markets. Recent research (Anderson and Wittwer, 2017) suggests potential scenario and consequences of this event for the global wine industry. Only in one case (Italy8) it was felt that, instead of affecting negatively trade, Brexit had actually contributed to more appreciation for Prosecco Superiore (DOCG): "Ironically, after the outcome of the referendum, consumption of our products in the UK increased... "Italy8 attributed such growth to the fact the United Kingdom (UK) importer had understood the winery's philosophy, and therefore was enthusiastic to start a business relationship and be prepared to assume higher costs (Italy8): "as opposed to the DOC, we are not competing in price but in quality; our DOCG products are marketed at a very different level."

Competition, a constant issue in the global wine industry (Anderson and Wittwer, 2017; Campbell and Guibert, 2006 Thomas et al., 2013), was another reason for participants' eagerness to internationalise. Moreover, while recognising the positive effects of Prosecco DOC, there were resulting challenges posed by direct competition for the perceived more upmarket and higher-quality Prosecco DOCG (Italy1): "We notice the competition from the Prosecco DOC, which clearly has much lower costs than our Prosecco Superiore and also has the capacity to produce much higher volumes."

A similar challenge was underlined by Spanish participants, namely, through the competition and influence of major wineries, notably, in pursuing a business philosophy of low margins that ultimately damaged the brand image of Cava, and therefore the entire industry. As Spain2 indicated: "The industry is already struggling and these companies lower the prices even further. Selling Cava at these low prices is plain and simple destroying the market that was mature and doing well..."

\section{Discussion}

Proposed theoretical framework

In reflecting on EAT and on the findings, various associations and alignments were revealed; these were further developed and depicted in the proposed theoretical framework (Figure 1). The academic literature underlines the importance of institutional, financial and technological factors that contribute to shaping successful entrepreneurship (Camufflo, Gerli, and Gubitta, 2012). However, as research conducted among small firms (Camufflo et al., 2012) highlights, equally important are entrepreneurs' alertness to opportunities, knowledge, imagination, creativity, and skills. Arguably, alertness represents a key element in response to uncertainty, and is therefore strongly associated with EAT. Indeed, while uncertainty can impede action and contribute to doubt, entrepreneurial alertness guarantees maximisation of opportunities, thus, helping perpetuate the market system (McMullen and Shepherd, 2006).

Alertness to opportunities, as well as other elements such as stimulus, motivation, and knowledge (McMullen and Shepherd, 2006), decision making, strategy, leadership, and, 
ultimately, sustaining competitive advantage, for instance, through speed in acting and tacit learning (Alvarez and Barney, 2007), are clearly reflected in this study. For example, while winery owners and managers had little or no control and influence over increased product popularity and demand, or a burgeoning wine tourism activity, they were resolute to take action and exploit the numerous opportunities for profit that these uncontrollable or even serendipitous events created. Moreover, operating in an uncertain environment due to changes and competitive forces (Costa-Font et al., 2009; Thiene et al., 2013), such externally favourable factors represent unique opportunities not to be ignored by the participating micro firm operators.

Similarly, it is vital to consider the wider factors affecting wine operators, where risks and political forces such as, for example, changing bureaucratic requirements, new trade tariffs and import/export rules have been a catalyst to internationalisation. As Spain8 explained: "If you secure prepayment and also learn where the bottles are sold, you learn how to minimise risks, not only financial but also image-related... Exports are vital for the future of this firm."

These issues constantly plague the management of smaller firms where appropriate consideration, resourcing and strategic oversight are required to deliver success (Banham, 2010). Indeed, these factors identified by wineries can drive a firm to action. Winery operators' concerns are not only part of the drivers for internalisation, but are also part of existing issues should firms seek this undertaking. Nonetheless, dealing with uncertainty and risk is part of organisational change and as Banham (2010) indicates, the starting point for assessing the external environment.

At the same time, winery operators were determined to address detrimental external events (Brexit, competition) that might threaten the financial health of the firm, even its long-term survival. Therefore, exploiting or maximising the various opportunities that presented themselves, either through direct and deliberate entrepreneurial action, or serendipitously, not only can satisfy personal desires (McMullen and Shepherd, 2006), but can also, and fundamentally, contribute to effective entrepreneurial actions. In the context of EAT, these phenomena which emerges externally, and beyond the control or influence of micro entrepreneurs, can be understood as opportunity attention (third person opportunities), or opportunities in general, which emerge through trends or changing consumer interests and demands. However, maximising the potential of the growth in wine tourism, or benefiting from the product's attractiveness (positive developments), are intrinsically linked to knowledge and motivation to act. For example, awareness of and information concerning these favourable events, complemented with micro firm operators' motivation to act, are essential antecedents of exploiting these general opportunities.

Furthermore, whether opportunities for internationalisation are the result of rather serendipitous events or deliberate strategies, they both entail opportunity evaluation and subsequent action in a variety of ways. Not surprisingly, some participants were resolute to work on product quality, product diversification, expanding and increasing partnerships and networks, as well as continuously focusing on building product image awareness:

Italy6: ...now we are even selling in France, which before was almost impossible... Overtime, however, French importers and consumers have understood that Prosecco can be a good product.

Spain2: We entered China with our red wines and now we are introducing our Cavas. In the United States... we started with Cava and now we are selling our still wines... right now we receive wine tourists... the word-of-mouth is quite strong in Australia and New Zealand for wine tourism.

Figure 1 Here 


\section{Conclusions}

In addressing various knowledge gaps (e.g., McCormick and Fernhaber, 2018; Musso and Francioni), and by examining the how and why of internationalisation, the present study contributed to the empirical and theoretical debate on micro firm internationalisation, and therefore to the academic literature. The findings demonstrated that micro firms were internationalising through various means, predominantly through exports and by benefitting from the growth of wine tourism. Furthermore, their rationale for internationalising was partly based on the current popularity of their product, as well as due to uncertainty, for instance, due to ongoing external concerns (Brexit, political issues), and to maximise the benefits of wine tourism (Table 3). These findings add to current discourse and affirm similar internationalisation approaches by wineries and within the country specific contexts of Italy and Spain. The study has also expanded understanding of the international activities undertaken by micro firms.

Furthermore, in accord with research on SME internationalisation in the high-tech environment (Crick and Spence, 2005), the internationalisation of these micro firms followed both anticipation and reaction, including reacting to external, uncontrollable factors. Importantly, serendipity emerged through the advent of the current popularity and preference of a product, predominantly among Italian participants, or through the growth of wine tourism, which appeared to be equally strong for both groups. While cross-country differences emerged in regards to the product's popularity, or political issues that triggered more interest and involvement in internationalisation activities, in most cases, both groups did not exhibit any significant differences.

Indeed, it was interesting to note that in a cross-country review, numerous similarities in the drivers and challenges to internationalisation were revealed. Based on the findings, there were a number of issues that were shared by and needed to be addressed in both Spanish and Italian contexts.

From a theoretical stance, the usefulness of EAT to understand both the how and why of micro firm internationalisation was reflected in the proposed framework (Figure 1). First, to address uncertainty, and as previously suggested, various serendipitous events supported the insightfulness of understanding opportunities in general through the lens of opportunity attention. Second, if managed efficiently, some of these events (increasing product popularity, wine tourism), as well as more deliberate strategies and involvement (increasing networks, more advertising and marketing) can present opportunities for profit to individual firms.

\section{Implications}

Various practical/managerial and theoretical implications can be drawn from this research. From a practical point of view, the findings clearly indicated two distinct forms of perceiving opportunities to internationalise. On one hand, owners and manager were deliberating seeking to increase their international involvement, particularly through exports, which in many cases start with the development of relationships and networks. Deliberate measures were implemented to address competition, concerns over political events (Spanish participants) and international (Brexit), and also to maximise opportunities that present themselves serendipitously, or without firm operators' initiatives. Thus, in agreement with Crick and Spence (2005), one fundamental implication is that the various forms and dimensions associated with micro firm internationalisation require a more holistic view. Moreover, as revealed in this study, the internationalisation process hinges upon various controllable and uncontrollable factors that render internationalisation of micro firms increasingly complex. 
While clearly there were barriers that result or exacerbate uncertainty, such as Brexit, or the reigning business or political climate that discourages growth or entrepreneurship, at the same time these and other factors were conducive to entrepreneurial action. The 'uncontrollable' yet emerging wine tourism phenomenon, or preference for out-of-the beaten path, less known brands that are not mass-produced represent avenues with important financial ramifications for micro wineries. With their niche production, and therefore uniqueness and differentiation potential, micro wineries are in a position to improve their position while addressing the challenges of uncertainty.

From a theoretical standpoint, a key implication derived from the proposed framework (Figure 1), which entails a number of dimensions (e.g., firms' environment, risk, political challenges) that could be interpreted, reflected upon, and considered, particularly in the context of internationalisation. Further, the framework underlined the significance of a 'trail of progression', starting at the opportunity attention stage concerning the different ways and possibilities available to the studied micro firms to maximise opportunities that could also be targeted by rival firms. The progression phase was then suggested to become strengthened by entrepreneurs' more direct involvement in the opportunity evaluation stage, notably, through more specific actions at an individual level. These actions included strategic ways of developing or further building upon ongoing, uncontrollable events, bringing these to a different level, where the firm is capable or ready to make more investments, or increase its engagement and involvement in internationalisation-related activities and efforts. At the same time, the framework provided a visual path into the different pitfalls or potential barriers that micro firms might encounter, and indeed some of the methods that are being undertaken to addressed these. In this context, given micro firms' more limited resources (Paul et al., 2017), and therefore more vulnerability to uncertain business settings, the framework also underscored the significance of exploiting those aspects where micro firms might have an advantage. Moreover, as previously noted, uniqueness and niche-batch production could be appealing elements to different consumer groups, including international importers, consumers, as well as international wine tourists. Thus, opportunity attention and evaluation become both vehicles in the process of spotting opportunities while minimising pitfalls, and as a result, they both might lead to internationalisation.

\section{Limitations and future research}

By nature, while qualitative research offers advantages, it also has limitations (Oparaocha, 2015). In tandem with previous literature, the study has not only extended knowledge into micro firms, but also affirmed much previous understanding into SMEs research.

Nonetheless, the study has focused on micro firms operating in the wine industry; therefore, while the conclusions are valid and can apply to current discourse, there needs to be careful consideration of their generalisability. Further and arguably, the framework (Figure 1) and its different elements might apply to other micro winery firms operating in the same or in other wine regions of Italy and Spain or in other geographic settings outside Southern Europe or to micro firms operating in other industries. However, in order to ascertain this applicability, further research is required. For example, future research could examine micro firms' internationalisation initiatives and involvement in other contexts and industries, applying the EAT-based framework, as well as considering it in combination with other theoretical foundations such as the resource-based view of the firm, dynamic capabilities approach, or social exchange theory.

Future studies could also examine the drivers and viability of internationalisation of micro firms in different countries, expanding upon diverse and differing activities. This line of research, which could include comparative explorations between emerging and consolidated, or North versus South Hemisphere nations, could create more complex cross-country 
comparatives. Future research may also choose to apply quantitative methodologies, either in testing the theories and framework developed by this study, or to extend further knowledge of internationalisation in micro firms.

\section{References}

Alvarez, S.A. and Barney, J.B. (2007), "Discovery and creation: Alternative theories of entrepreneurial action", Strategic Entrepreneurship Journal, Vol. 1 No. 1-2, pp. 1126.

Anderson, K. and Wittwer, G. (2017), "UK and global wine markets by 2025, and implications of Brexit", Journal of Wine Economics, Vol. 12 No. 3, pp. 221-251.

Andersson, S., Gabrielsson, J. and Wictor, I. (2004), "International activities in small firms. Examining factors influencing the internationalization and export growth of small firms", Canadian Journal of Administrative Science, Vol. 21 No. 1, pp. 22-34.

Banham, H.C. (2010), "External environmental analysis for small and medium enterprises (SMEs)", Journal of Business and Economics Research, Vol. 8 No. 10, pp. 19-26.

Bell, J., Crick, D. and Young, S. (2004), "Small firm internationalization and business strategy: an exploratory study of 'knowledge-intensive' and 'traditional' manufacturing firms in the UK", International Small Business Journal, Vol. 22 No. 1, pp. 23-56.

Bettiol, M., Di Maria, E. and Finotto, V. (2012), "Marketing in SMEs: the role of entrepreneurial sensemaking", International Entrepreneurship and Management Journal, Vol. 8 No. 2, pp. 223-248.

Bowen, G.A. (2008), "Naturalistic inquiry and the saturation concept: a research note", Qualitative Research, Vol. 8 No. 1, pp. 137-152.

Campbell, G. and Guibert, N. (2006), "Introduction: Old World strategies against New World competition in a globalising wine industry", British Food Journal, Vol. 108 No. 4, pp. 233-242.

Cerrato, D., Crosato, L. and Depperu, D. (2016), “Archetypes of SME internationalization: A configurational approach”, International Business Review, Vol. 25 No. 1, pp. 286295.

Conegliano-Valdobbiadene (2016), “Annual Report, 2016, DOCG; Controlled and Guaranteed Designation of Origin, Soligheto, Italy", available at: http://www.prosecco.it/wpcontent/uploads/2015/06/2016rapporto_annualeConeglianoValdobbiadene.pdf (accessed June 6 2018).

Costa-Font, M., Serra, T., Gil, M. and Gras, A. (2009), "Explaining low farm-gate prices in the Catalan wine sector", International Journal of Wine Business Research, Vol. 21 No. 2, pp. 169-184.

Crick, D. and Spence, M. (2005), “The internationalisation of 'high performing' UK hightech SMEs: a study of planned and unplanned strategies", International Business Review, Vol. 14 No. 2, pp. 167-185.

D'Angelo, A., Majocchi, A., Zucchella, A. and Buck, T. (2013), "Geographical pathways for SME internationalization: insights from an Italian sample", International Marketing Review, Vol. 30 No. 2, pp. 80-105.

Dean, T.J. and McMullen, J.S. (2007), "Toward a theory of sustainable entrepreneurship: Reducing environmental degradation through entrepreneurial action", Journal of Business Venturing, Vol. 22 No. 1, pp. 50-76.

DO Cava (2018), "Economic figures 2017”, available at: 
http://www.docava.es/wp-content/uploads/2018/04/dosier17-cava-esp.pdf (accessed May 26 2018).

Dominguez, N. and Mayrhofer, U. (2017), "Internationalization stages of traditional SMEs: Increasing, decreasing and re-increasing commitment to foreign markets", International Business Review, Vol. 26 No. 6, pp. 1051-1063.

Donner, J. (2006), "The use of mobile phones by microentrepreneurs in Kigali, Rwanda: Changes to social and business networks", Information Technologies and International Development, Vol. 3 No. 2, pp-3-19.

Duarte Alonso, A., Bressan, A., O'Shea, M. and Krajsic, V. (2014), "Exporting wine in complex times: A study among small and medium wineries", Journal of Small Business and Enterprise Development, Vol. 21 No. 2, pp. 345-364.

Duarte Alonso, A., Bressan, A., O'Shea, M. and Krajsic, V. (2015), "Perceived benefits and challenges to wine tourism involvement: An international perspective", International Journal of Tourism Research, Vol. 17 No. 1, pp. 66-81.

Dutot, V., Bergeron, F. and Raymond, L. (2014), "Information management for the internationalization of SMEs: An exploratory study based on a strategic alignment perspective", International Journal of Information Management, Vol. 34 No. 5, pp. 672-681.

European Commission (2016), “Annual Report on European SMEs", available at: https://ec.europa.eu/jrc/sites/jrcsh/files/annual_report_-_eu_smes_2015-16.pdf (accessed June 26 2018).

European Commission (2003), "What is an SME?", available at: http://ec.europa.eu/growth/smes/business-friendly-environment/sme-definition_en (accessed June 9 2018).

Fusch, P.I. and Ness, L.R. (2015), "Are we there yet? Data saturation in qualitative research", The Qualitative Report, Vol. 20 No. 9, pp. 1408-1416.

García-Horta, J.B. and Guerra-Ramos, M.T. (2009), "The use of CAQDAS in educational research: Some advantages, limitations and potential risks", International Journal of Research and Method in Education, Vol. 32 No. 2, pp. 151-165.

Gartner, W. B. (1990). What are we talking about when we talk about entrepreneurship? Journal of Business Venturing, Vol. 5 No. 1, pp. 15-28.

Gronn, P. (2002), "Distributed leadership as a unit of analysis. The Leadership Quarterly, Vol. 13 No. 4, pp. 423-451.

Hébert, R.F. and Link, A.N. (1988), The entrepreneur: Mainstream views and radical critiques $2^{\text {nd }}$ ed., Praeger, New York.

Hermel, P. and Khayat, I. (2011), "The role of resources: micro-firms internationalization in the French context", Journal of Small Business and Enterprise Development, Vol. 18 No. 2, pp. 298-310.

Hsieh, H-F and Shannon, S.E. (2005), "Three approaches to qualitative content analysis", Qualitative Health Research, Vol. 15 No. 9, pp. 1277-1288.

Kent, C.A., Sexton, D.L., and Vesper, K.H. (1982), Encyclopedia of entrepreneurship, Prentice-Hall, Englewood Cliffs, NJ.

Madhok, A. and Keyhani, M. (2012), “Acquisitions as entrepreneurship: Asymmetries, opportunities, and the internationalization of multinationals from emerging economies", Global Strategy Journal, Vol. 2 No. 1, pp. 26-40.

McCormick, M. and Fernhaber, S. A. (2018), "Are growth expectations being met? Implications for the internationalization of micro-sized ventures", Small Business Economics, Vol. 50 No. 3, pp. 591-605.

McKelvie, A., Haynie, J.M. and Gustavsson, V. (2011), "Unpacking the uncertainty construct: Implications for entrepreneurial action", Journal of Business 
Venturing, Vol. 26 No. 3, pp. 273-292.

McMullen, J.S. and Shepherd, D.A. (2006), "Entrepreneurial action and the role of uncertainty in the theory of the entrepreneur", Academy of Management Review, Vol. 31 No. 1, pp. 132-152.

Melin, L. (1992), "Internationalization as a strategy process", Strategic Management Journal, Vol. 13 No. S2, pp. 99-118.

Mises, L.V. (1949), Human action: A treatise on economics ( $4^{\text {th }}$ revised ed.), Fox and Wilkes, San Francisco, CA.

Mitchell, J.R. and Shepherd, D.A. (2010), "To thine own self be true: Images of self, images of opportunity, and entrepreneurial action", Journal of Business Venturing, Vol. 25 No. 1, pp. 138-154.

Musso, F. and Francioni, B. (2015), "Agri-food clusters, wine tourism and foreign markets. The role of local networks for SMEs' internationalization", Procedia Economics and Finance, Vol. 27, pp. 334-343.

Musteen, M., Francis, J. and Datta, D.K. (2010), "The influence of international networks on internationalization speed and performance: A study of Czech SMEs", Journal of World Business, Vol. 45 No. 3, pp. 197-205.

Oparaocha, G.O. (2015), "SMEs and international entrepreneurship: An institutional network perspective", International Business Review, Vol. 24 No. 5, pp. 861-873.

O'Reilly, M and N Parker (2013), 'Unsatisfactory Saturation': a critical exploration of the notion of saturated sample sizes in qualitative research", Qualitative Research, Vol. 13 No. 2, pp. 190-197.

Patton, MQ (2015), Qualitative research and evaluation methods (4 ${ }^{\text {th }}$ ed.). SAGE Publications, Inc., Los Angeles, CA.

Paul, J., Parthasarathy, S. and Gupta, P. (2017), "Exporting challenges of SMEs: A review and future research agenda", Journal of World Business, Vol. 52 No. 3, pp. 327-342.

Ponterotto, J.G. (2005), "Qualitative research in counseling psychology: A primer on research paradigms and philosophy of science", Journal of Counseling Psychology, Vol. 52 No. 2, pp. 126-136.

Raymond, L. and St-Pierre, J. (2013), "Strategic capability configurations for the internationalization of SMEs: A study in equifinality", International Small Business Journal, Vol. 31 No. 1, pp. 82-102.

Shane, S. and Venkataraman, S. (2000), "The promise of entrepreneurship as a field of research", Academy of Management Review, Vol. 25 No. 1, pp. 217-226.

Schumpeter, J.A. (1934), Change and the entrepreneur. Harvard University Press, Cambridge, MA.

Statista (2020a). Wine production worldwide in 2019, by country, https://www.statista.com/statistics/240638/wine-production-in-selected-countries-andregions/ (accessed June 27 2020).

Statista (2020b). Leading countries in wine export worldwide in 2019, based on volume, https://www.statista.com/statistics/240649/top-wine-exporting-countries-since-2007/ (accessed June 27 2020).

Thiene, M., Galletto, L., Scarpa, R. and Boatto, V. (2013), "Determinants of WTP for Prosecco wine: A latent class regression with attitudinal responses", British Food Journal, Vol. 115 No. 2, pp. 279-299.

Thomas, D.R. (2006), “A general inductive approach for analyzing qualitative evaluation data", American Journal of Evaluation, Vol. 27 No. 2, pp. 237-246.

Thomas, L. C., Painbéni, S. and Barton, H. (2013), "Entrepreneurial marketing within the French wine industry", International Journal of Entrepreneurial Behavior and Research, Vol. 19 No. 2, pp. 238-260. 
Welch, L.S. and Luostarinen, R. (1988), "Internationalization: Evolution of a concept. Journal of General Management, Vol. 14 No. 2, pp. 34-55.

Westhead, P., Wright, M. and Ucbasaran, D. (2004), "Internationalization of private firms: environmental turbulence and organizational strategies and resources", Entrepreneurship and Regional Development, Vol. 16 No. 6, pp. 501-522.

Woodside, A.G., and Baxter, R. (2013), "Achieving accuracy, generalization-to-contexts, and complexity in theories of business-to-business decision processes. Industrial Marketing Management, Vol. 42, pp. 382-393.

Zhang, X., Ma, X., Wang, Y., Li, X. and Huo, D. (2016), "What drives the internationalization of Chinese SMEs? The joint effects of international entrepreneurship characteristics, network ties, and firm ownership", International Business Review, Vol. 25 No. 2, pp. 522-534.

Zhao, H., Seibert, S.E. and Lumpkin, G.T. (2010), "The relationship of personality to entrepreneurial intentions and performance: A meta-analytic review", Journal of Management, Vol. 36 No. 2, pp. 381-404. 